\title{
High-Speed (Subsecond) Measurement of Heat Capacity, Electrical Resistivity, and Thermal Radiation Properties of Tantalum in the Range 1900 to 3200 K*
}

\author{
A. Cezairliyan, J. L. McClure, and C. W. Beckett \\ Institute for Materials Research, National Bureau of Standards, \\ Washington, D.C. 20234
}

(September 11, 1970)

\begin{abstract}
Measurements of heat capacity, electrical resistivity, hemispherical total and normal spectral emittances of tantalum above $1900 \mathrm{~K}$ by a pulse heating technique are described. Duration of an individual experiment, in which the specimen is heated from room temperature to near its melting point, is less than one second. Temperature measurements are made with a photoelectric pyrometer. Experimental quantities are recorded with a digital data acquisition system. Time resolution of the entire system is $0.4 \mathrm{~ms}$. Results on the above properties of tantalum in the range 1900 to $3200 \mathrm{~K}$ are reported and are compared with those in the literature. Estimated inaccuracy of measured properties in the above temperature range is 2 to 3 percent for heat capacity, 0.5 percent for electrical resistivity, 3 percent for hemispherical total emittance, and 2 percent for normal spectral emittance.
\end{abstract}

Key words: Electrical resistivity; emittance; heat capacity: high-speed measurements; high temperature; tantalum; thermal radiation properties; thermodynamics.

\section{Introduction}

Conventional methods of measuring heat capacity, electrical resistivity, and other thermophysical properties at high temperatures employ "drop", steadystate, and quasi steady-state techniques in which the specimen is exposed to high temperatures for long periods of time, ranging from minutes to hours. Extension of these techniques to temperatures above $2000 \mathrm{~K}$ creates problems resulting from increased heat transfer, chemical reactions, evaporation, diffusion, loss of mechanical strength, etc. To overcome these limitations, this laboratory has recently developed a highspeed measurement technique in which the specimen is heated and pertinent quantities required for the determination of properties are measured in short times. The duration of an individual experiment, in which the specimen is heated from room temperature to near its melting point, is less than $1 \mathrm{~s}$. A millisecond resolution photoelectric pyrometer is used to measure the specimen temperature. The recordings of experimental quantities are made with a high-speed digital data acquisition system, which has a time resolution of $0.4 \mathrm{~ms}$. The application of this technique to measurements on molybdenum has been published [1]. ${ }^{1}$ General reviews on high-speed methods for the measurement of thermophysical properties of electrical conductors have been presented recently $[2,17]$.

*This work was supported in part by the Propulsion Division of the U.S. Air Force Office of Scientific Research under contract ISSA-69-0001.

Figures in brackets indicate the literature references at the end of this paper.
In the present study the technique was used to determine the heat capacity and electrical resistivity of tantalum in the temperature range 1900 to $3200 \mathrm{~K}$, and the hemispherical total and normal spectral emittances up to $3000 \mathrm{~K}$.

\section{Method}

The method employed in this study is based upon rapid resistive heating of the specimen by the passage of high currents and measuring the pertinent quantities with appropriate time resolution. The required quantities are the power imparted to the specimen and the temperature of the specimen, both as functions of time. Imparted power is obtained from measurements of current flowing through the specimen and the potential difference across the "effective" ${ }^{2}$ specimen as a function of time.

The relationship for heat capacity is obtained from power balances for the specimen during the pulse heating and the following free cooling periods. The expression for heat capacity, which was derived in an earlier publication [1], is

$$
c_{p}=\frac{e i-\epsilon \sigma A_{s}\left(T^{4}-T_{0}^{4}\right)}{n(d T / d t)_{h}}
$$


where

$$
\begin{aligned}
c_{p}= & \text { heat capacity in } \mathrm{J} \mathrm{mol}^{-1} \mathrm{~K}^{-1} \\
e= & \text { potential difference across the effective } \\
& \text { specimen in } V \\
i= & \text { current through the specimen in } A \\
\epsilon= & \text { hemispherical total emittance } \\
\sigma= & \text { Stephan-Boltzmann constant }(5.6697 \\
& \left.\times 10^{-8} W m^{-2} K^{-4}\right) \\
A_{s}= & \text { effective specimen surface area in } m^{2} \\
T= & \text { specimen temperature in } \mathrm{K} \\
T_{0}= & \text { room temperature in } \mathrm{K} \\
n= & \text { amount of effective specimen in mol } \\
(d T / d t)_{h}= & \text { heating rate in } \mathrm{K} s^{-1}
\end{aligned}
$$

The hemispherical total emittance, $\epsilon$, which appears in the radiation loss term of the heat capacity relation, is determined from data collected during the free cooling period. Derived from the power balance relationship during the cooling period and eq (1), the expression for $\epsilon$ is

$$
\epsilon=\frac{e i}{\sigma A_{s}\left(T^{4}-T_{0}^{4}\right)(1+M)}
$$

where

$$
M=-\frac{(d T / d t)_{h}}{(d T / d t)_{c}}
$$

$$
(d T / d t)_{c}=\text { cooling rate in } \mathrm{K} \mathrm{s}^{-1}
$$

Equation (2) is used to compute values for $\epsilon$ at selected temperatures, which are used to obtain a function for $\epsilon$ in terms of temperature. Then, $\epsilon$ values from this function are substituted in eq (1) to obtain heat capacity over the entire temperature range.

Data from the heating period is also used to calculate the electrical resistivity with the aid of the equation

$$
\rho=\frac{R A_{c}}{l}
$$

where

$$
\begin{aligned}
\rho & =\text { electrical resistivity in } \Omega \mathrm{m} \\
R & =\text { resistance of effective specimen in } \Omega \\
A_{c} & =\text { specimen cross-sectional area in } \mathrm{m}^{2} \\
l & =\text { effective specimen length in } \mathrm{m} .
\end{aligned}
$$

The normal spectral emittance, $\epsilon_{n, \lambda}$, is obtained from separate pulse experiments in which radiance from the surface of the specimen is measured. The relation for $\epsilon_{n, \lambda}$ is

$$
\epsilon_{n, \lambda}=\frac{L_{s}}{L_{b}}
$$

where

$L_{s}=$ radiance from surface of specimen as observed by the pyrometer.

$L_{b}=$ blackbody radiance from sighting hole in specimen as observed by the pyrometer.

In all the above equations, geometrical quantities are corrected for the presence of the sighting hole, and the quantities related to radiation from the sighting hole are corrected for scattered light and departure from blackbody conditions.

\section{Apparatus}

A functional diagram of the measurement system used in this study is shown in figure l. The details of the system were described in an earlier publication [1].

The specimen was a tube approximately $100 \mathrm{~mm}$ long with a small rectangular hole fabricated in the wall at the middle of its length to approximate blackbody conditions. The knife-edge probes, which were used for potential measurements, were made of tantalum and were placed $50 \mathrm{~mm}$ apart on the middle portion of the specimen. The portion between the probes, defined as "effective" specimen, was free from significant temperature gradients for the duration of an experiment. The specimen and the associated components were contained in a vacuum chamber.

The specimen temperature was measured with a high-speed photoelectric pyrometer [12], which permits 1200 evaluations of the specimen temperature per second. The pyrometer alternately compares the radiance from the blackbody hole in the specimen to that of a reference lamp.

Electrical signals corresponding to voltage, current, and temperature were recorded with a high-speed digital data acquisition system, which consists of a multiplexer, analog-to-digital converter, and a core memory together with various control and interfacing equipment. At the end of each experiment, the data were retrieved and recorded in printed numeric form and on punched paper tape via a teletypewriter. During this retrieval period, data were also sent to a timesharing computer for immediate processing.

Electrical signals corresponding to voltage, current, and temperature were also monitored simultaneously with oscilloscopes.

\section{Measurements}

Measurements were made on four tantalum specimens. The first two specimens were used for experiments in the temperature interval 1900 to $3000 \mathrm{~K}$. To optimize the operation of the pyrometer, this temperature interval was divided into three ranges with three experiments per range. These nine experiments are referred to as a series. The temperature ranges were: low, 1900 to $2250 \mathrm{~K}$; medium, 2100 to $2600 \mathrm{~K}$; and high, 2350 to $3000 \mathrm{~K}$. 


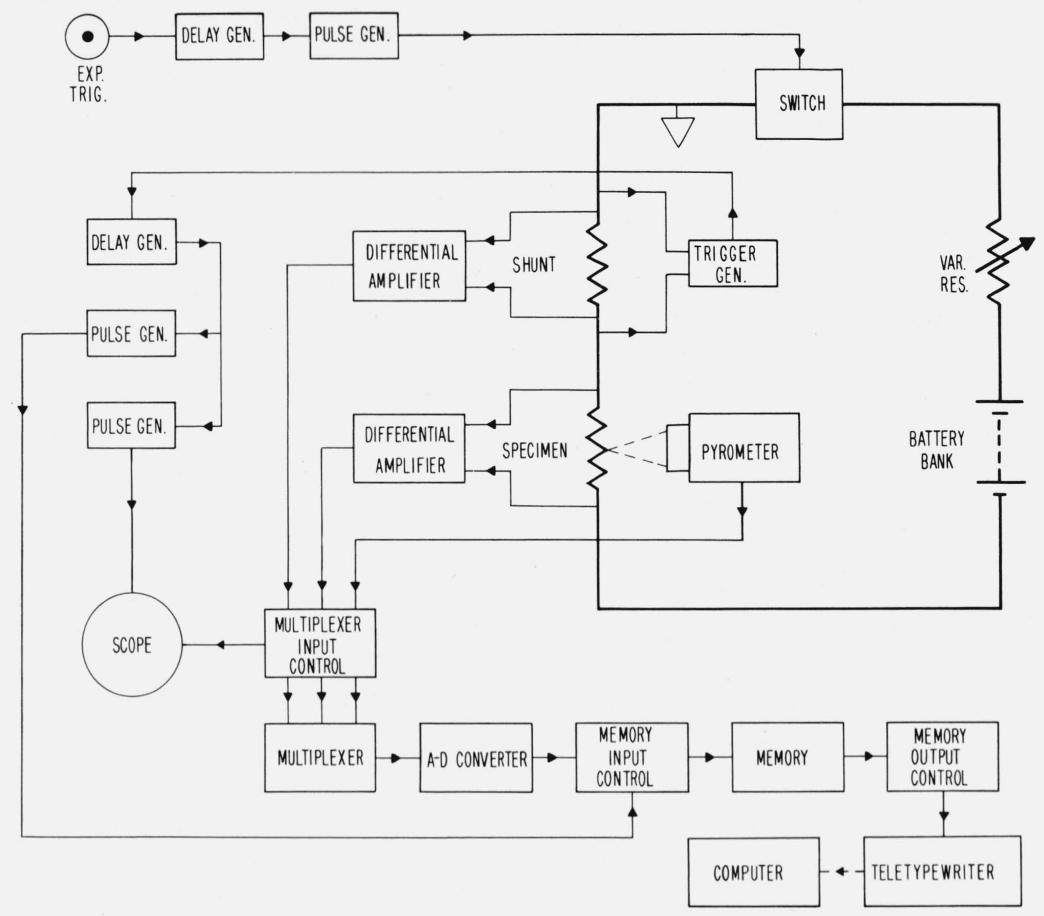

FIGURE 1. Functional diagram of the complete high-speed measurement system.

Two complete series of experiments were conducted on the first specimen $(\mathrm{Ta}-1)$. During the second series, two additional experiments were conducted, one in the low range and one in the high range, to measure the surface radiance of the specimen. Before the start of the first series of experiments, the specimen $(\mathrm{Ta}-1)$ was subjected to approximately 30 heating pulses (in the range 2200 to $3000 \mathrm{~K}$ ) to anneal the specimen and to determine the optimum heating rate for each temperature range. At the end of the first series of experiments and before the start of the second series, the specimen was pulse heated 15 times to $3000 \mathrm{~K}$. One experiment per temperature range was conducted on the second specimen $(\mathrm{Ta}-2)$ without any prior heating pulses.

To obtain heat capacity and electrical resistivity in the temperature range 2950 to $3200 \mathrm{~K}$, two other specimens, $(\mathrm{Ta}-3)$ and $(\mathrm{Ta}-4)$, were used.

The duration of the current pulses ranged from 280 to $520 \mathrm{~ms}$ depending on the temperature. The average heating rate of the specimen was 5700 and $3700 \mathrm{~K} \mathrm{~s}^{-1}$ at 2000 and $3200 \mathrm{~K}$, respectively. At these temperatures, radiative heat losses from the specimen amounted to approximately 3 and 22 percent of the input power, respectively. All of the experiments were conducted with the specimen in a vacuum environment of approximately $10^{-4}$ torr.

The data on voltage, current, and temperature were used to obtain third degree polynomial functions for each quantity in terms of time, which then provided the input information for the equations of section 2 .

During the entire set of experiments, the pyrometer was calibrated five times against a tungsten filament standard lamp, which in turn was calibrated against the NBS Temperature Standard. The digital recording system including the differential amplifiers was calibrated three times during the experiments. The details of the calibration procedures are given in an earlier publication [1].

Prior to the start of the experiments, the optical system of the pyrometer was modified to reduce the effect of light scattered from the area around the sighting hole in the specimen. In the present system this effect is approximately one percent. The blackbody quality of the specimen sighting hole was estimated to be 0.99 using DeVos' [13] method. The temperature data from the pyrometer were corrected for both scattered light and departure from blackbody conditions. The details of the methods employed for these corrections are given in an earlier publication [1].

The nominal dimensions of the tubular tantalum specimens were: length $=4$ in $(101 \mathrm{~mm})$, outside diameter $=0.25$ in $(6.3 \mathrm{~mm})$, and wall thickness $=0.02$ in $(0.5 \mathrm{~mm})$. The outer surface of each specimen was polished to reduce heat loss due to thermal radiation.

Specimen characterization was made on one specimen $(\mathrm{Ta}-1)$ by the following methods: photomicrography, chemical analysis, and residual resistivity ratio.

Photomicrographs of the specimen before and after the entire set of experiments are shown in figure 2 . It may be seen that considerable grain growth has taken place as the result of pulse heating the specimen to high temperatures.

Chemical analyses were made of the specimen before and after the entire set of experiments. Comparison of results does not indicate any detectable change in impurity content. A list of the nature and composition of impurities in the specimen is given in table 1 . 

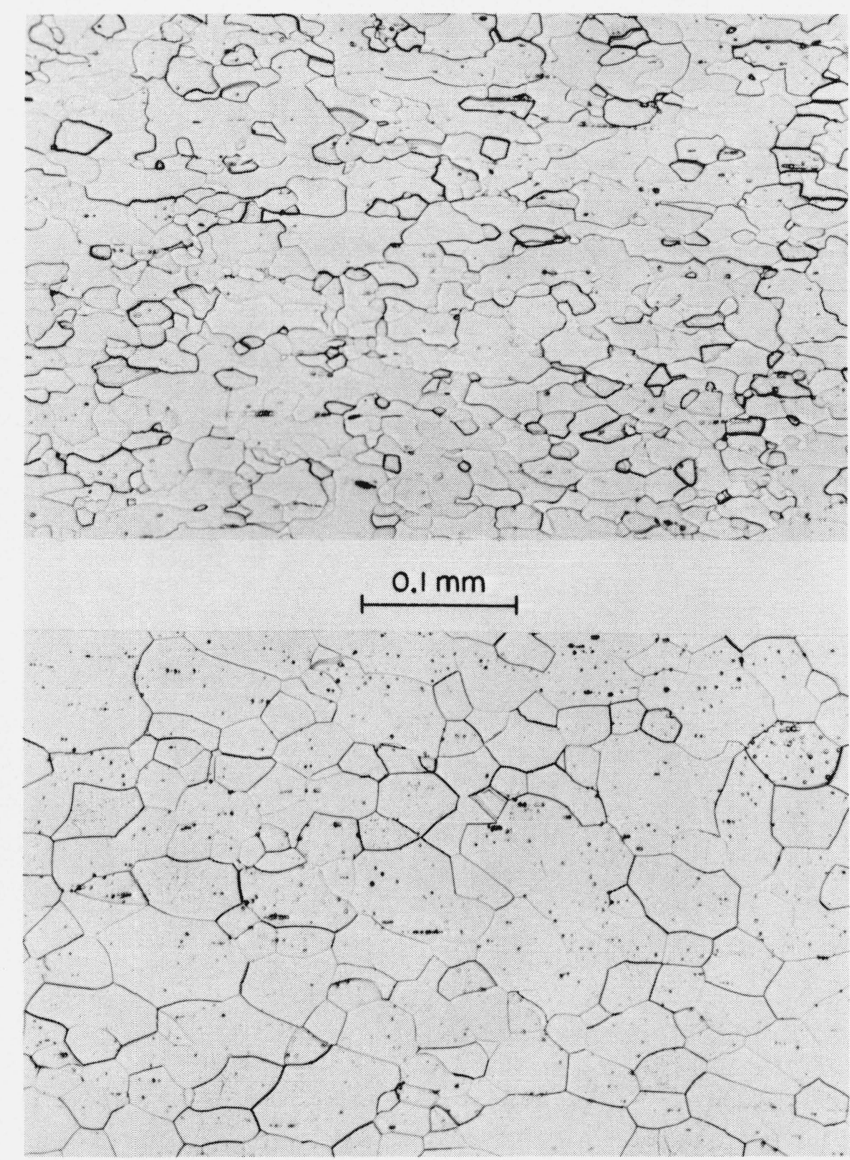

FigURE 2. Photomicrographs of the tantalum specimen before (upper photograph) and after (lower photograph) the entire set of experiments.

TABLE 1. Impurities in tantalum specimen

\begin{tabular}{c|c}
\hline \hline Impurity & $\begin{array}{c}\text { Composition ppm } \\
\text { (by weight) }\end{array}$ \\
\hline $\mathrm{Al}$ & $<5$ \\
$\mathrm{C}$ & 60 \\
$\mathrm{Ca}$ & $<5$ \\
$\mathrm{Cr}$ & $<10$ \\
$\mathrm{Cu}$ & $<5$ \\
$\mathrm{Fe}$ & 70 \\
$\mathrm{Mg}$ & $<5$ \\
$\mathrm{Mo}$ & 10 \\
$\mathrm{~N}$ & 20 \\
$\mathrm{Nb}$ & 500 \\
$\mathrm{O}$ & 50 \\
$\mathrm{~W}$ & $<200$ \\
\hline
\end{tabular}

$710<$ Total $<940$

The residual resistivity ratio of the specimen (ratio of electrical resistivity at $273 \mathrm{~K}$ to that at $4 \mathrm{~K}$ ) before and after the entire set of experiments was $22 \pm 1$. The fact that the value of this ratio remained unchanged indicates that the specimen did not undergo any major chemical or physical changes.

The total mass of the specimen was determined before and after each series of experiments. The "effec- tive" mass of the specimen was calculated from the total mass by ratio of the geometric surface area between voltage probes to total surface area. Length measurements at room temperature were made with a micrometer microscope to the nearest $0.03 \mathrm{~mm}$. The thickness of the cylinder wall was calculated from the mass, surface areas, and density.

Density of tantalum at $298 \mathrm{~K}$ was obtained by the water displacement method in a pycnometer. The results of three determinations gave a value of 16.65 $\times 10^{3} \mathrm{~kg} \mathrm{~m}^{-3}$ with an average deviation of 0.03 percent. This compares favorably with the reported value of $16.6 \times 10^{3} \mathrm{~kg} \mathrm{~m}^{-3}[16]$.

\section{Experimental Results}

This section presents the results on the thermophysical properties determined from the measured quantities. All values are based on the 1968 International Practical Temperature Scale [14]. The final results on properties at 100 degree temperature intervals are presented in table 2 . In all computations, the geometrical quantities are based on their ambient temperature (298 K) dimensions. The experimental results (individual points) on properties are given in the appendix (tables $\mathrm{A}-1$ to $\mathrm{A}-5$ ).

TABLE 2. Heat capacity, electrical resistivity, hemispherical total and normal spectral emittances of tantalum

\begin{tabular}{c|c|r|r|r}
\hline \hline $\begin{array}{c}\text { Tempera- } \\
\text { ture, K }\end{array}$ & $\begin{array}{c}c_{p} \\
\mathrm{~mol}^{-1} \mathrm{~K}^{-1}\end{array}$ & $\begin{array}{c}\rho^{\mathrm{a}} \\
10^{-8} \Omega \mathrm{m}\end{array}$ & $\epsilon^{\mathrm{a}}$ & $\epsilon_{N, \lambda}$ \\
\hline 1900 & 30.66 & 75.56 & $\mathrm{~b} 0.288$ & ${ }^{\mathrm{b}} 0.413$ \\
2000 & 31.19 & 78.80 & $\mathrm{~b} .293$ & .411 \\
2100 & 31.71 & 82.00 & $\mathrm{~b} .298$ & .409 \\
2200 & 32.25 & 85.14 & $\mathrm{~b} .302$ & .407 \\
2300 & 32.83 & 88.23 & .307 & .406 \\
2400 & 33.46 & 91.26 & .312 & .404 \\
2500 & 34.17 & 94.24 & .316 & .403 \\
2600 & 34.97 & 97.17 & .321 & .401 \\
2700 & 35.89 & 100.04 & .326 & .400 \\
2800 & 36.95 & 102.86 & .330 & .400 \\
2900 & 38.16 & 105.63 & .335 & .399 \\
3000 & 39.55 & 108.34 & .340 & .398 \\
3100 & 41.39 & 111.00 & & \\
3200 & 44.48 & 113.60 & & \\
\hline
\end{tabular}

a Based on ambient temperature (298 K) dimensions.

${ }^{\text {b }}$ Extrapolated from higher temperature results.

\subsection{Normal Spectral Emittance}

To calculate the normal spectral emittance, two experiments were performed to measure the surface radiance of the $\mathrm{Ta}^{-1}$ specimen during the second heating series. The measurements were made at the effective wavelength of the pyrometer interference filter $(650 \mathrm{~nm}$; bandwidth $10 \mathrm{~nm})$. The normal spectral emittance was calculated using the radiance data from each surface experiment together with the data from a previous or later regular blackbody experiment 
according to eq (5). Since the specimen's true temperature could not be measured directly in a surface experiment, the times at which the resistance of the specimen in the two adjacent experiments were equal were taken as the times of equal temperature.

A second degree polynomial function for normal spectral emittance was obtained by least squares approximation of the experimental results. The standard deviation (of an individual point) is 0.3 percent. The function that is valid in the temperature range 2000 to $3000 \mathrm{~K}$ is:

$$
\begin{gathered}
\epsilon_{n, \lambda}=0.4892-5.644 \times 10^{-5} T+8.734 \times 10^{-9} T^{2} \\
\quad(\text { second series })
\end{gathered}
$$

Normal spectral emittance computed using the above equation is given in table 2 . The experimental results are presented in figure 3 .

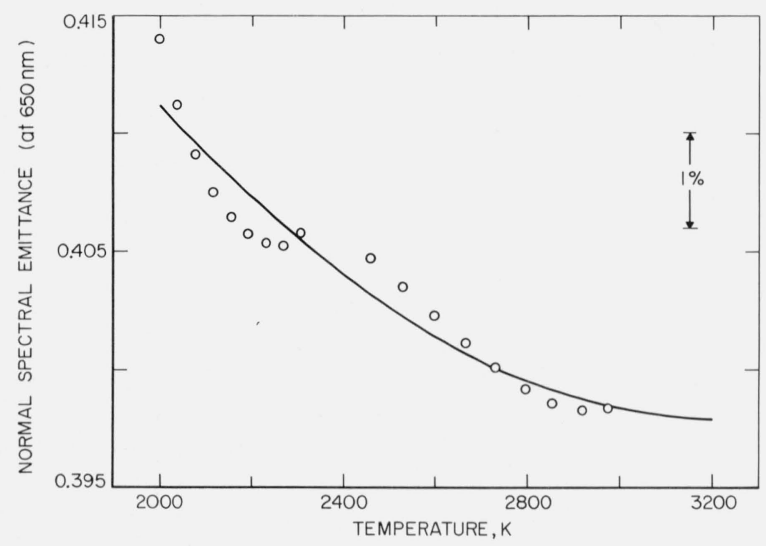

FigURE 3. Normal spectral emittance of tantalum at $\lambda=650 \mathrm{~nm}$.

\subsection{Hemispherical Total Emittance}

The hemispherical total emittance of the Ta-1 specimen was computed with the aid of eq (2) using temperature data taken during both heating and initial free cooling periods in an experiment.

A linear function for hemispherical total emittance for each heating series was obtained by least squares approximation of the individual values. The standard deviation of the points from the function for the first and second heating series were 0.7 and 0.5 percent, respectively. The functions that are valid in the temperature range 2300 to $3000 \mathrm{~K}$ are:

$$
\begin{aligned}
& \epsilon=0.2197+4.146 \times 10^{-5} T \quad \text { (first series) } \\
& \epsilon=0.1991+4.687 \times 10^{-5} T \quad \text { (second series) }
\end{aligned}
$$

Hemispherical total emittance computed using eq (8) is given in table 2 . The experimental results are presented in figure 4.

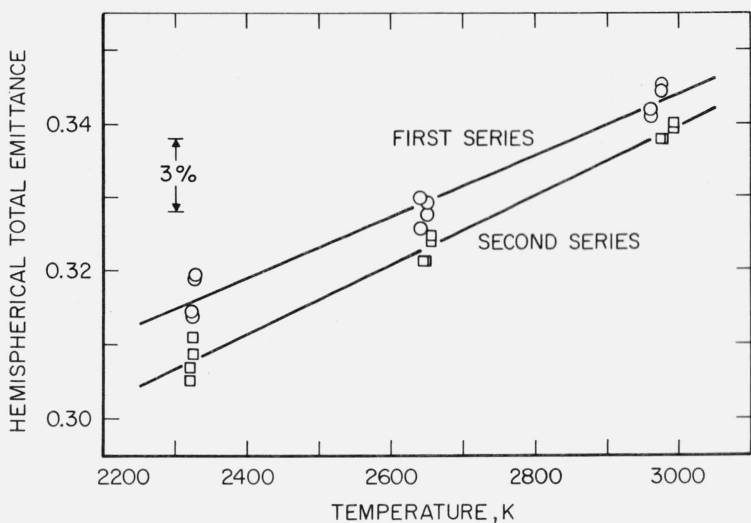

Figure 4. Hemispherical total emittance of tantalum.

\subsection{Heat Capacity}

A third degree polynomial function for heat capacity in terms of temperature for each heating series on $\mathrm{Ta}-1$ was obtained by least squares approximation of results from individual experiments. The standard deviation of the points from the function for the first and second heating series were 0.19 and 0.17 percent, respectively. A similar function was also obtained for the combined results of experiments in the first and second series with a standard deviation of 0.18 percent.

Figure 5 shows the deviations of the experimental results from the smooth function for the combined heating series. The figure also shows the deviation of the function for each individual heating series from the heat capacity function for the combined series. Compared to the function for the combined series, the average difference between the functions for the first and second heating series is about 0.1 percent, which is smaller than the measurement resolution. Therefore, it may be concluded that the measured heat capacity shows no significant difference between the two heating series. The function for the combined series that is valid in the temperature range 1900 to $3000 \mathrm{~K}$ is:

$$
\begin{aligned}
c_{p}=-6.549+ & 4.583 \times 10^{-2} T \\
& -2.013 \times 10^{-5} T^{2}+3.325 \times 10^{-9} T^{3}
\end{aligned}
$$

where $T$ is in $\mathrm{K}$ and $c_{p}$ in $\mathrm{J} \mathrm{mol}^{-1} \mathrm{~K}^{-1}$. Heat capacity up to $3000 \mathrm{~K}$ computed using the above equation is given in table 2 . In the computations of heat capacity, the atomic weight of tantalum was taken as 180.95 [15].

Without any prior heating pulses, three experiments were conducted on a second tantalum specimen (Ta-2). Figure 6 shows the difference in measured heat capacity between $\mathrm{Ta}-1$ and $\mathrm{Ta}-2$. The base line in figure 6 represents the smooth function for heat capacity of $\mathrm{Ta}^{-1}$ given by eq (9). The maximum deviation between the heat capacity results of the two specimens occurs at the lowest temperature and is less than 1 percent. The tendency for the heat capacity of $\mathrm{Ta}-2$ to approach that of $\mathrm{Ta}-1$ as the temperature increases may be due to annealing effects as the temperature range for the $\mathrm{Ta}-2$ specimen was increased. 


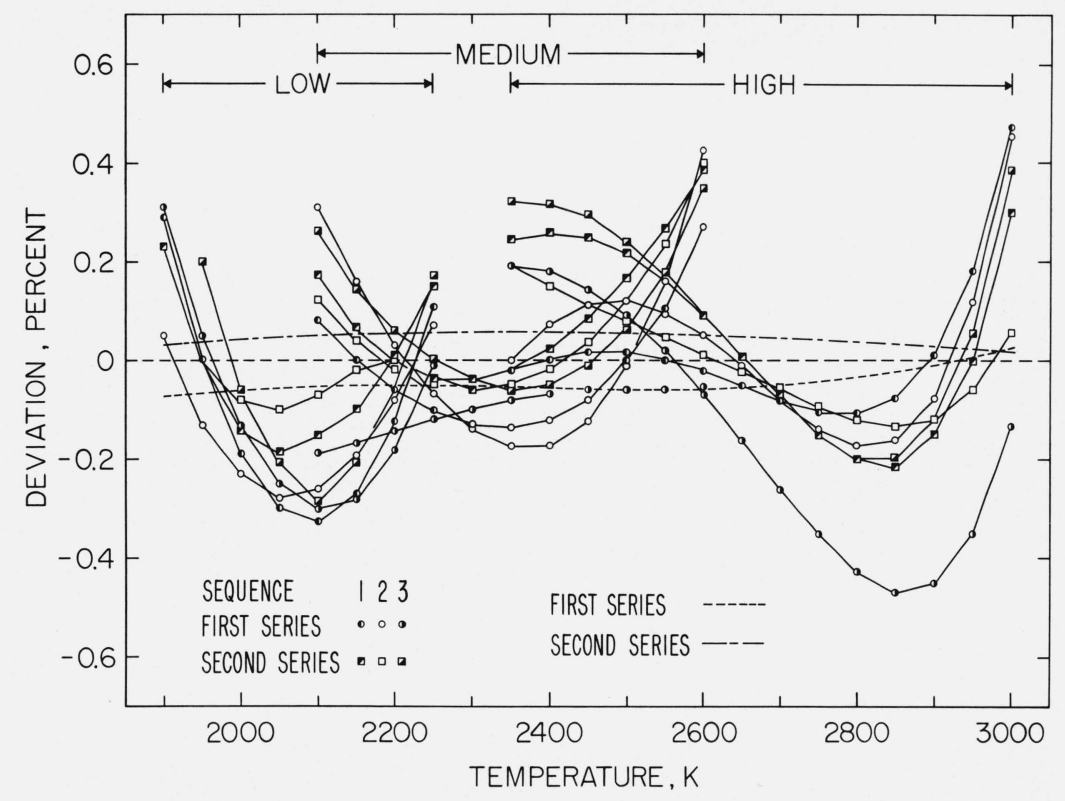

FIGURE 5. Deviation of heat capacity results for tantalum from eq (9).

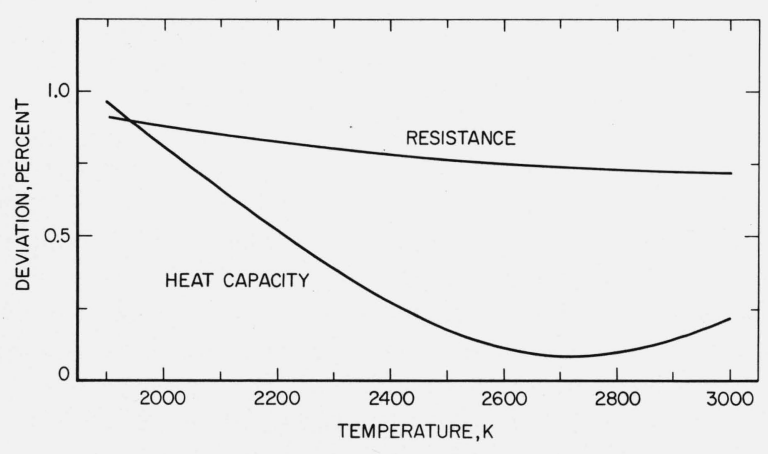

FIGURE 6. Difference in heat capacity and electrical resistivity between two tantalum specimens.

Base line represents results for $\mathrm{Ta}-1$ given by eqs $(9)$ and (10).

The preliminary results on heat capacity of tantalum up to $3000 \mathrm{~K}$ were reported in an earlier publication [3]. In this study the measurements were extended to $3200 \mathrm{~K}$ by performing one experiment each on $\mathrm{Ta}-3$ and $\mathrm{Ta}-4$, and averaging the results. Hemispherical total emittance needed to correct heat capacity above $3000 \mathrm{~K}$ was obtained from the extrapolation of the experimental results at lower temperatures. The results of measurements above $3000 \mathrm{~K}$ are given in table 2 . At $3000 \mathrm{~K}$ the heat capacity for this extended temperature range is approximately 0.1 percent lower than the value given by eq (9).

\subsection{Electrical Resistivity}

The electrical resistivity of the $\mathrm{Ta}-1$ specimen was determined from the same experiments that were used to calculate the heat capacity. A second degree polynomial function for each heating series was obtained by least squares approximation of results from individual experiments. The standard deviation of the points from the function for the first and second heating series are 0.03 and 0.02 percent, respectively.

In contrast to the heat capacity results, the electrical resistivity showed a small but significant difference between the two heating series; the results of the second series being lower than those of the first. The combined data from both heating series were fitted to a second degree polynomial function. Figure 7 shows the deviations of the experimental results from the smooth function for the combined series. The figure also shows the deviation of the function for each individual heating series from the electrical resistivity function for the combined series. The average difference between the functions for the first and second heating series is approximately 0.15 percent. The function for the combined series that is valid for the temperature range 1900 to $3000 \mathrm{~K}$ is:

$$
\rho=3.671+4.292 \times 10^{-2} \mathrm{~T}-2.677 \times 10^{-6} T^{2}
$$

where $T$ is in $\mathrm{K}$ and $\rho$ in $10^{-8} \Omega \mathrm{m}$. Electrical resistivity up to $3000 \mathrm{~K}$ computed using the above equation is given in table 2 .

The difference between the results on $\mathrm{Ta}^{-1}$ and $\mathrm{Ta}-2$ is presented graphically in figure 6 . In contrast to heat capacity, electrical resistivity did not converge as $\mathrm{Ta}-2$ was exposed to high temperatures.

The results of experiments on $\mathrm{Ta}-3$ and $\mathrm{Ta}-4$ were used to compute electrical resistivity above $3000 \mathrm{~K}$. These are included in table 2. At $3000 \mathrm{~K}$ electrical resistivity obtained from $\mathrm{Ta}-3$ and $\mathrm{Ta}-4$ was approximately 0.3 percent lower than the value given by eq (10). 


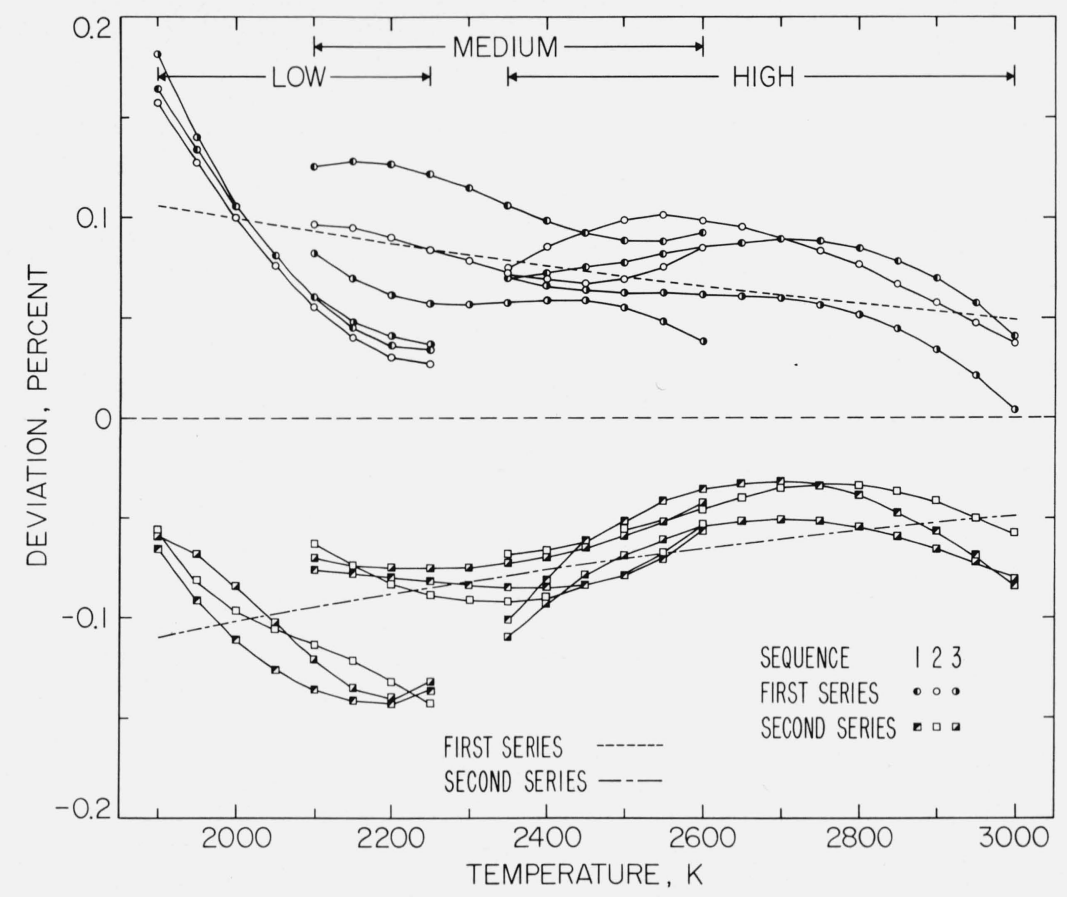

FigURE 7. Deviation of electrical resistivity results for tantalum from eq (10).

In addition, the electrical resistivity of $\mathrm{Ta}^{-1}$ was measured at $293 \mathrm{~K}$ under steady-state conditions. The resultant value was $14.0 \times 10^{-8} \Omega \mathrm{m}$.

\section{Estimate of Errors}

Results on imprecision ${ }^{3}$ and inaccuracy ${ }^{4}$ of measured and computed quantities are given in table 3.

TABLE 3. Imprecision and inaccuracy of measured and computed quantities

\begin{tabular}{|c|c|c|}
\hline Quantity & $\begin{array}{l}\text { Imprecision } \\
\text { (percent) }\end{array}$ & $\begin{array}{c}\text { Inaccuracy } \\
\text { (percent) }\end{array}$ \\
\hline Temperature ............ & $0.02(0.5 \mathrm{~K})$ & $\left\{\begin{array}{l}0.2(4 \mathrm{~K}) \text { at } 2000 \mathrm{~K} \\
0.3(10 \mathrm{~K}) \text { at } 3200 \mathrm{~K}\end{array}\right.$ \\
\hline 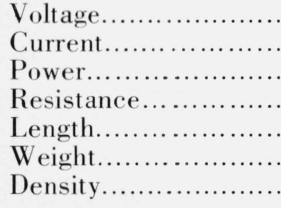 & $\begin{array}{r}0.02 \\
.03 \\
.04 \\
.04 \\
.04 \\
.01 \\
.03\end{array}$ & $\begin{array}{r}0.05 \\
.06 \\
.08 \\
.08 \\
.08 \\
.1 \\
.1\end{array}$ \\
\hline Heat Capacity.......... & .5 & $\left\{\begin{array}{l}2 \text { at } 2000 \mathrm{~K} \\
3 \text { at } 3200 \mathrm{~K}\end{array}\right.$ \\
\hline $\begin{array}{l}\text { Resistivity } \ldots \ldots \ldots \ldots \ldots \\
\text { Hem. Total Emit- } \\
\quad \text { tance.......................... }\end{array}$ & $\begin{array}{l}.04 \\
.7\end{array}$ & 3.5 \\
\hline $\begin{array}{l}\text { Norm. Spectral Emit- } \\
\text { tance....................... }\end{array}$ & .3 & 2 \\
\hline
\end{tabular}

${ }^{3}$ Imprecision refers to the standard deviation of an individual point as computed from the difference between measured and calculated values.

${ }^{4}$ Inaccuracy refers to the estimated maximum error (random and systematic) approximately equivalent to two standard deviations.
Numbers listed under imprecision were obtained from a least squares analysis of experimental results. Numbers listed under inaccuracy were estimated considering the contribution of various items that introduce random and systematic errors in the pertinent quantities. These items are listed below:

(a) In temperature measurements: pyrometer reproducibility, scattered light correction, light source alinement, radiation standard lamp, blackbody quality, specimen temperature uniformity, magnetic fields.

(b) In electrical measurements: skin effect, inductive effects, thermoelectric effects.

(c) In interpretation of results: specimen evaporation, thermionic emission, time synchronization, measurements of length and weight.

Details regarding the estimates of errors and their combination are given in another publication [1]. Specific items in the error analysis were recomputed whenever the present conditions differed from those in the earlier publication.

\section{Discussion}

The heat capacity and electrical resistivity results of this work are compared graphically with those in the literature in figures 8 and 9, respectively. Numerical comparisons are given in tables 4 and 5 . It may be seen that present results agree favorably with all others at $2000 \mathrm{~K}$ and also at higher temperatures, with the exception of heat capacity results of Hoch and Johnston [8]. Estimates of errors in papers cited lead to an estimate of inaccuracies in previously reported heat capacity and electrical resistivity of approxi- 


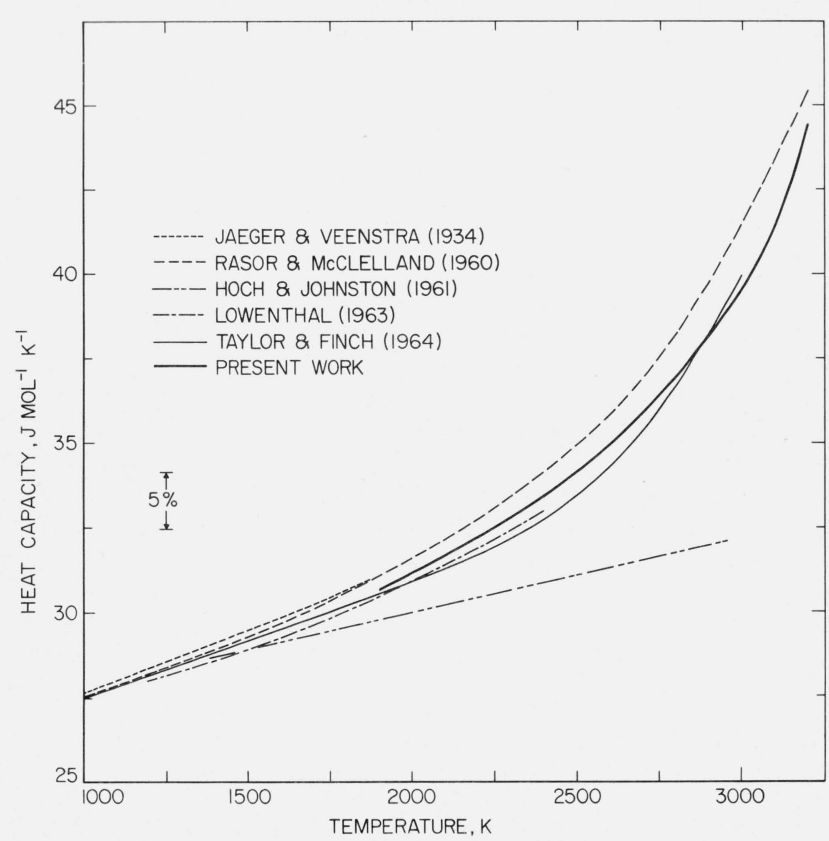

FIGURE 8. Heat capacity of tantalum reported in the literature.

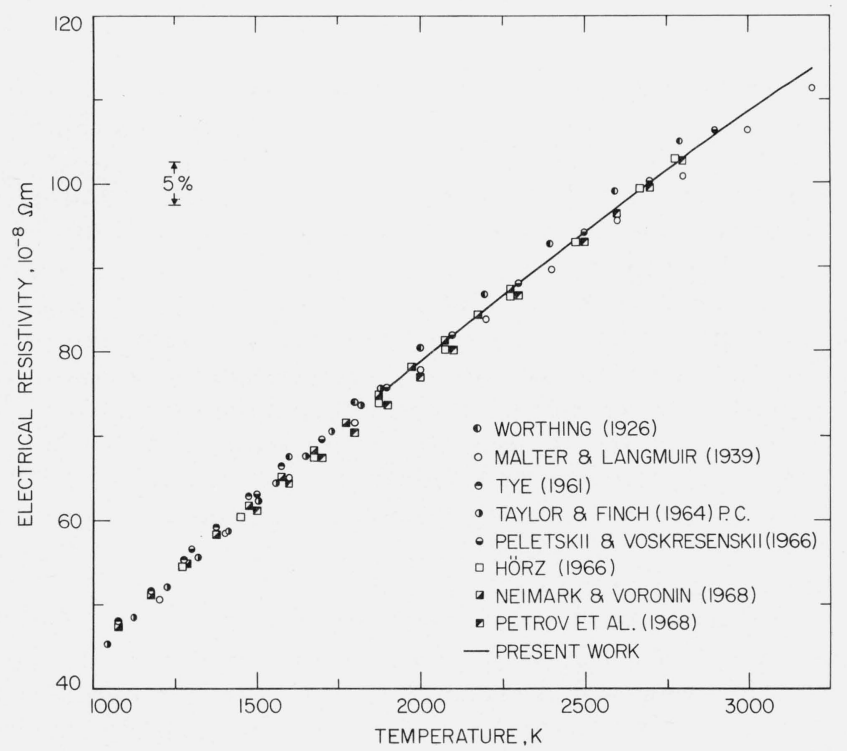

FIGURE 9. Electrical resistivity of tantalum reported in the literature. mately 5 to 10 and 1 to 3 percent, respectively, in the temperature range considered. Measurements of the electrical resistivity of tantalum corresponding to $293 \mathrm{~K}$, as well as values reported in the literature, are given in table 6 .

The results for hemispherical total and normal spectral emittances of this work and those in the literature are presented in figures 10 and 11 , respectively. Because of the strong dependence of emittance on surface conditions, considerable deviations exist in the results of various investigators.

Heat capacity results at high temperatures are considerably higher than the Dulong and Petit value of $3 R$. Some of this departure is due to $c_{p}-c_{v}$ and the electronic terms. However, they do not account for the entire departure. Heat capacity above the Debye temperature may be expressed by

$$
c_{p}=A-\frac{B}{T^{2}}+C T+\Delta c
$$

where the constant term is $3 R\left(24.943 \mathrm{~J} \mathrm{~mol}^{-1} \mathrm{~K}^{-1}\right)$, the term in $T^{-2}$ is the first term in the expansion of the Debye function, the term in $T$ represents $c_{p}-c_{v}$ and electronic contributions, and the quantity $\Delta c$ represents excess in measured heat capacity at high temperatures, which is not accounted for by the first three terms. The coefficients $B\left(4.88 \times 10^{4}\right)$ and $C(2.59$

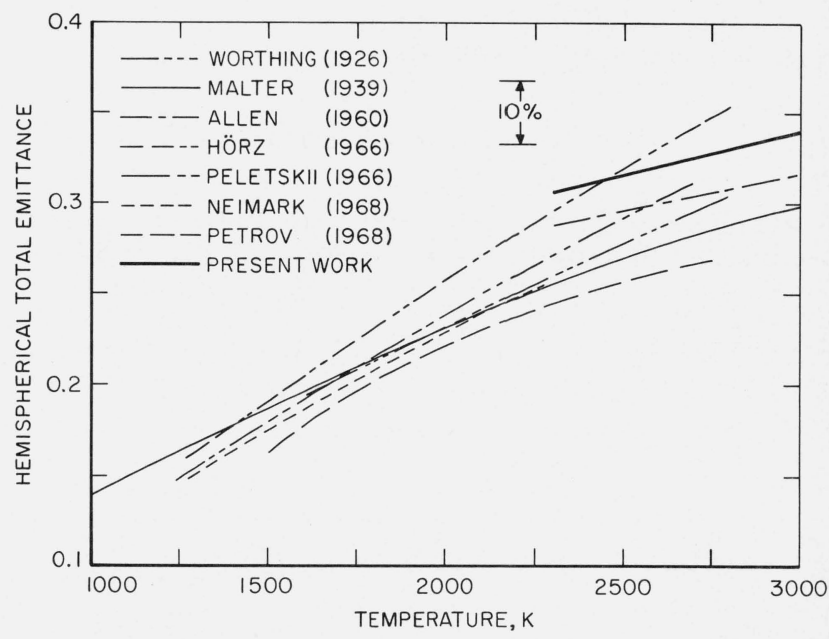

FIGURE 10. Hemispherical total emittance of tantalum reported in the literature.

TABLE 4. Tantalum heat capacity difference (previous literature values minus present work values) in percent

\begin{tabular}{|c|c|c|c|c|c|c|c|c|c|c|}
\hline \multirow{2}{*}{ Investigator } & \multirow{2}{*}{ Ref. } & \multirow{2}{*}{ Year } & \multirow{2}{*}{ Method } & \multicolumn{7}{|c|}{ Temperature, $\mathrm{K}$} \\
\hline & & & & 2000 & 2200 & 2400 & 2600 & 2800 & 3000 & 3200 \\
\hline $\begin{array}{l}\text { Jaeger and Veenstra....... } \\
\text { Rasor and McClelland..... } \\
\text { Hoch and Johnston......... } \\
\text { Lowenthal.................. } \\
\text { Taylor and Finch........... }\end{array}$ & $\begin{array}{l}7 \\
5 \\
8 \\
4 \\
6\end{array}$ & $\begin{array}{l}1934 \\
1960 \\
1961 \\
1963 \\
1964\end{array}$ & $\begin{array}{l}\text { drop } \\
\text { pulse } \\
\text { drop } \\
\text { modul. } \\
\text { pulse }\end{array}$ & $\begin{array}{r}\mathrm{a}+1.2 \\
+1.3 \\
-3.8 \\
-0.8 \\
-0.9\end{array}$ & $\begin{array}{l}+1.4 \\
-5.6 \\
-1.0 \\
-1.6\end{array}$ & $\begin{array}{l}+1.9 \\
-7.6 \\
-1.3 \\
-2.2\end{array}$ & $\begin{array}{r}+2.4 \\
-10.4 \\
-1.9\end{array}$ & $\begin{array}{r}+3.4 \\
-14.0 \\
-0.8\end{array}$ & $\begin{array}{l}+5.0 \\
+0.9\end{array}$ & +2.0 \\
\hline
\end{tabular}

${ }^{\text {a }}$ Extrapolated from $1873 \mathrm{~K}$. 
TABLE 5. Tantalum electrical resistivity difference (previous literature values minus present work values) in percent

\begin{tabular}{|c|c|c|c|c|c|c|c|c|c|}
\hline \multirow{2}{*}{ Investigator } & \multirow{2}{*}{ Ref. } & \multirow{2}{*}{ Year } & \multicolumn{7}{|c|}{ Temperature, $\mathrm{K}$} \\
\hline & & & 2000 & 2200 & 2400 & 2600 & 2800 & 3000 & 3200 \\
\hline Worthing. & 18 & 1926 & +2.3 & +2.1 & +2.1 & +2.2 & +2.4 & & \\
\hline Malter and Langmuir. & 19 & 1939 & -1.2 & -1.3 & -1.5 & -1.6 & -1.8 & -1.9 & -2.0 \\
\hline Peletskii and Voskresenskii. & 21 & 1966 & +0.2 & -0.1 & -0.1 & +0.1 & +0.4 & & \\
\hline Ḧ̈rz............. & 20 & 1966 & -1.0 & -0.8 & -0.4 & +0.1 & +0.9 & & \\
\hline Neimark and Voronin.. & 22 & 1968 & +0.4 & +0.2 & & & & & \\
\hline Petrov et al.. & 23 & 1968 & -2.1 & -1.8 & -1.4 & -0.8 & -0.1 & & \\
\hline
\end{tabular}

TABLE 6. Electrical resistivity of tantalum at $293 \mathrm{~K}$ (literature)

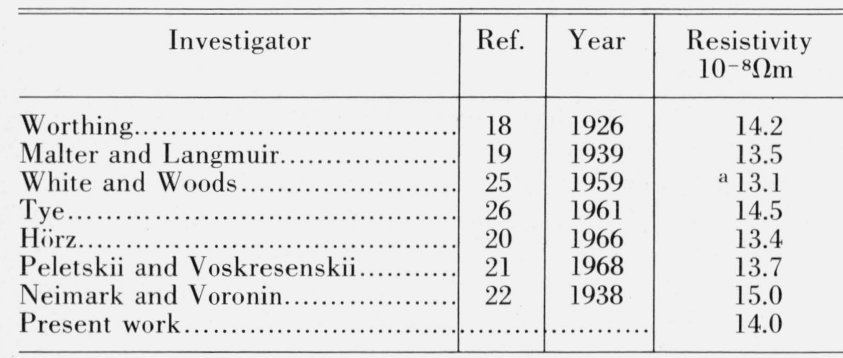

${ }^{\text {a }}$ Ideal resistivity.

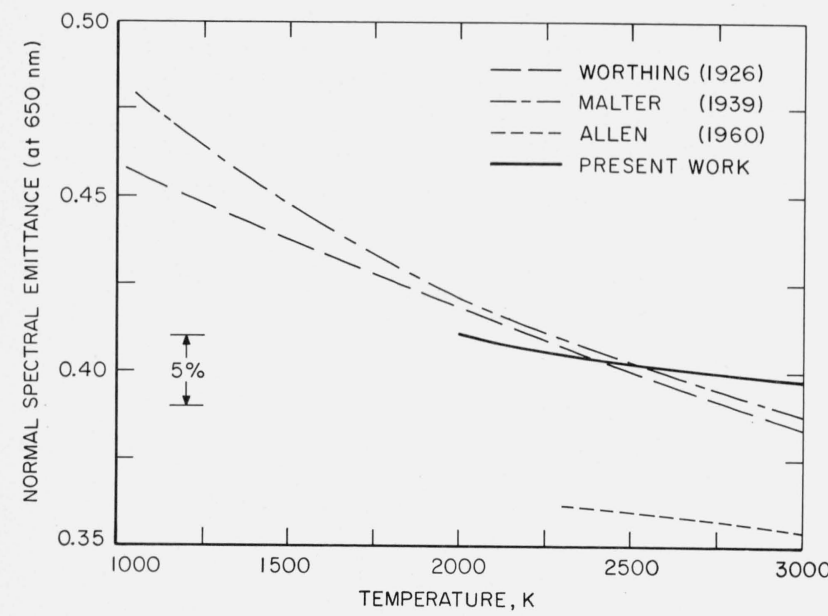

FIGURE 11. Normal spectral emittance of tantalum at $\lambda^{\prime}=650 \mathrm{~nm}$ reported in the literature.

$\times 10^{-3}$ ) were obtained from data on heat capacity at low and moderate temperatures (at 250 and $1000 \mathrm{~K}$ ) given by Hultgren et al. [11].

Using eq (11) and the heat capacity results of this work, the quantity $\Delta c$ was computed for temperatures above $1900 \mathrm{~K}$. The results are tabulated in table 7 . The estimated uncertainty in the computed $\Delta c$ may be as high as $1 \mathrm{~J} \mathrm{~mol}^{-1} \mathrm{~K}^{-1}$. This was obtained from the combined uncertainties in the coefficients in eq (11) and the measured heat capacities.
TABLE 7. Excess heat capacity $\Delta \mathrm{c}$ in equation (11) and estimated vacancy contribution to heat capacity of tantalum

\begin{tabular}{c|c|c}
\hline \hline$T$ & $\Delta c$ \\
$\mathrm{~K}$ & $\mathrm{~J} \mathrm{~mol}^{-1} \mathrm{~K}^{-1}$ & $\begin{array}{c}c_{\mathrm{vac}} \\
\mathrm{J} \mathrm{mol}^{-1} \mathrm{~K}^{-1}\end{array}$ \\
\hline 2000 & 1.08 & 0.003 \\
2200 & 1.62 & .01 \\
2400 & 2.31 & .04 \\
2600 & 3.30 & .10 \\
2800 & 4.76 & .21 \\
3000 & 6.84 & .41 \\
3200 & 9.70 & .73 \\
\hline
\end{tabular}

Although the mechanisms of vacancy generation become important at high temperatures, it was not possible to attribute the high values entirely to vacancies. To demonstrate this, a crude estimate of the contribution of vacancies to heat capacity was made using the following equation [1]:

$$
c_{\mathrm{vac}}=\frac{N_{A} A E_{f}^{2}}{k T^{2}} e^{-E_{f} / k T}
$$

where

$N_{A}=$ Avogadro's number

$k=$ Boltzmann constant

$E_{f}=$ vacancy formation energy

$A=$ constant which is obtained from vacancy concentration at the melting point.

If one assumes that vacancy formation energy is approximately proportional to the melting point and considers the value of $3.3 \mathrm{eV}$ reported by Schultz [9] for tungsten, one obtains $2.9 \pm 0.5 \mathrm{eV}$ for the vacancy formation energy for tantalum. There are no accurate measurements on tantalum related to vacancy concentrations. Results of quenching experiments on various refractory elements $[9,10]$ have indicated that vacancy concentrations are probably in the range 0.01 to 0.1 percent at their melting points. Estimates corresponding to a vacancy concentration of 0.1 percent at the melting point and a vacancy formation energy of $2.9 \mathrm{eV}$ are given in table 7 . The results indicate that vacancy contribution is small, less than $0.7 \mathrm{~J} \mathrm{~mol}^{-1} \mathrm{~K}^{-1}$ (upper limit) at $3200 \mathrm{~K}$, and does not account for high heat capacity values. A 
possible contribution of higher order terms in the electronic heat capacity may partially account for high values of heat capacity at high temperatures.

If the entire deviation of measured heat capacity from the sum of $3 R$ and the linear term at high temperatures is represented by an expression similar to eq (12), one could obtain after rearrangement

$$
\ln \left(T^{2} \Delta c\right)=\ln I-\frac{S}{T}
$$

This equation indicates that a plot of the left side versus $1 / T$ should yield a straight line with slope equal to $-S$. From the data on tantalum in the range 1900 to $3200 \mathrm{~K}$, a straight line with a standard deviation of 0.8 percent was obtained. However, the parameters obtained through this fit do not seem to have any physical significance. As a crude analogy to vacancy concentration, the computations yielded a value of $1.4 \mathrm{eV}$ for energy and 4.2 percent for concentration at the melting point. Both of these values seem to be unrealistic for tantalum.

In order to give a simple expression for the heat capacity of tantalum over a wide temperature range, an empirical term in $T^{5}$ for the quantity $\Delta c$ in eq (11) was substituted. The coefficient of this term was obtained from the results of the present work in conjunction with the values given by Hultgren et al. [11] at temperatures below $1000 \mathrm{~K}$. Then, eq (11) for the range 300 to $3100 \mathrm{~K}$ becomes

$$
\begin{aligned}
c_{p}=24.943-\frac{4.88 \times 10^{4}}{T^{2}}+2.59 & \times 10^{-3} T \\
& +2.85 \times 10^{-17} T^{5}
\end{aligned}
$$

where $T$ is in $\mathrm{K}$ and $c_{p}$ in $\mathrm{J} \mathrm{mol}^{-1} \mathrm{~K}^{-1}$. Average deviation of the individual points from the function over the temperature range considered is 0.4 percent. Equation (14) is presented graphically in figure 12.

The $T^{-2}$ term in eq (14) corresponds to a Debye $\theta$ of approximately $200 \mathrm{~K}$ for tantalum. This value is some- what lower than the generally accepted value of $247 \mathrm{~K}$ [28]. Such a deviation may be expected since in the above analysis only data above $250 \mathrm{~K}$ were considered while determinations reported in the literature were based on more elaborate treatment of lower temperature data.

It was interesting to note that the difference in heat capacity between $\mathrm{Ta}-1$ and $\mathrm{Ta}-2$ was reduced from approximately 1 percent at $1900 \mathrm{~K}$ to 0.2 percent at $3000 \mathrm{~K}$. The convergence of the results as $\mathrm{Ta}-2$ was exposed to high temperatures indicates the difference in the initial states of the two specimens; $\mathrm{Ta}-1$ was preheated while $\mathrm{Ta}-2$ was used as received from the manufacturer prior to the start of the measurements.

There was a small, but significant difference in electrical resistivity between the two heating series of $\mathrm{Ta}-1$. The second series results, which were lower than those of the first by approximately 0.15 percent, indicate that the specimen had undergone additional annealing during its exposure to high temperatures.

Unlike most metallic elements, the electrical resistivity of tantalum, in the range of present measurements, showed a negative departure from linearity in the curve of electrical resistivity against temperature. A small Fermi energy is believed to be responsible for some of this negative departure [27].

The experimental results reported in this paper have further substantiated the feasibility of accurate measurement of heat capacity and electrical resistivity of electrical conductors above approximately $2000 \mathrm{~K}$ by a pulse method of millisecond resolution. The results also indicated that under proper surface and environmental conditions the technique allows the measurement of hemispherical total and normal spectral emittances.

The authors extend their appreciation to M. S. Morse for his contribution in connection with electronic instrumentation, which is a vital part of the entire measurement system.

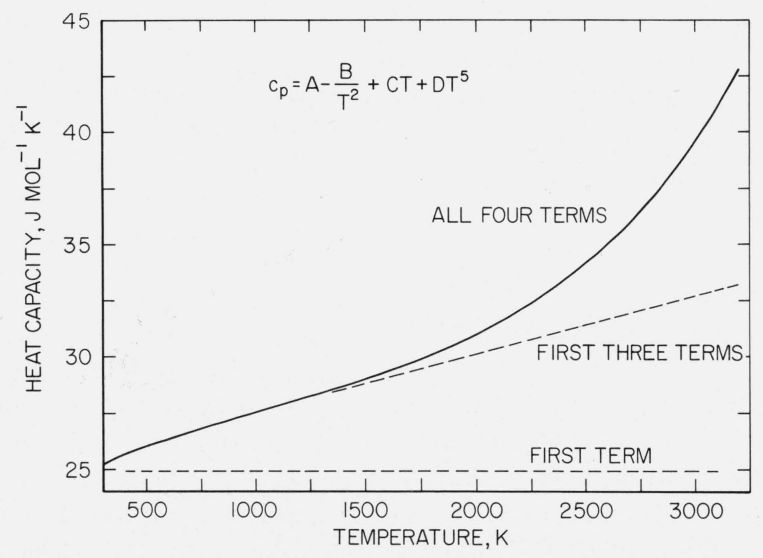

FigURE 12. Heat capacity of tantalum according to eq (14). 


\section{Appendix}

TABLE A-1. Experimental results on heat capacity and electrical resistivity of tantalum- $l^{\text {a }}$

\begin{tabular}{|c|c|c|c|c|c|c|c|c|c|c|c|c|c|}
\hline \multirow{3}{*}{ Range } & \multirow{3}{*}{$\begin{array}{c}\text { Series } \\
\text { Run } \\
T\end{array}$} & \multicolumn{6}{|c|}{ First series } & \multicolumn{6}{|c|}{ Second series } \\
\hline & & \multicolumn{2}{|c|}{1} & \multicolumn{2}{|c|}{2} & \multicolumn{2}{|c|}{3} & \multicolumn{2}{|c|}{1} & \multicolumn{2}{|c|}{2} & \multicolumn{2}{|c|}{3} \\
\hline & & $c_{p}$ & $\rho$ & $c_{p}$ & $\rho$ & $c_{p}$ & $\rho$ & $c_{p}$ & $\rho$ & $c_{p}$ & $\rho$ & $c_{p}$ & $\rho$ \\
\hline \multirow{8}{*}{ Low } & 1900 & 30.75 & 75.68 & 30.67 & 75.68 & 30.75 & 75.70 & 30.73 & 75.51 & 30.73 & 75.52 & 30.83 & 75.51 \\
\hline & 1950 & 30.92 & 77.29 & 30.88 & 77.29 & 30.94 & 77.30 & 30.92 & 77.12 & 30.92 & 77.13 & 30.98 & 77.14 \\
\hline & 2000 & 31.12 & 78.89 & 31.11 & 78.89 & 31.14 & 78.89 & 31.14 & 78.72 & 31.16 & 78.73 & 31.16 & 78.74 \\
\hline & 2050 & 31.35 & 80.48 & 31.36 & 80.47 & 31.36 & 80.47 & 31.39 & 80.31 & 31.41 & 80.33 & 31.38 & 80.33 \\
\hline & 2100 & 31.60 & 82.05 & 31.62 & 82.05 & 31.61 & 82.05 & 31.65 & 81.89 & 31.68 & 81.91 & 31.63 & 81.90 \\
\hline & 2150 & 31.88 & 83.62 & 31.91 & 83.61 & 31.88 & 83.62 & 31.94 & 83.46 & 31.96 & 83.48 & 31.91 & 83.46 \\
\hline & 2200 & 32.20 & 85.17 & 32.22 & 85.17 & 32.18 & 85.18 & 32.25 & 85.02 & 32.24 & 85.03 & 32.22 & 85.02 \\
\hline & 2250 & 32.56 & 86.72 & 32.55 & 86.72 & 32.52 & 86.72 & 32.57 & 86.57 & 32.51 & 86.57 & 32.58 & 86.58 \\
\hline \multirow{11}{*}{ Med. } & 2100 & 31.73 & 82.10 & 31.80 & 82.08 & 31.65 & 82.07 & 31.76 & 81.94 & 31.74 & 81.95 & 31.79 & 81.94 \\
\hline & 2150 & 31.97 & 83.69 & 32.02 & 83.66 & 31.92 & 83.64 & 31.99 & 83.51 & 31.98 & 83.52 & 32.02 & 83.52 \\
\hline & 2200 & 32.22 & 85.25 & 32.25 & 85.22 & 32.20 & 85.19 & 32.24 & 85.07 & 32.24 & 85.07 & 32.26 & 85.08 \\
\hline & 2250 & 32.49 & 86.80 & 32.50 & 86.77 & 32.49 & 86.74 & 32.51 & 86.62 & 32.51 & 86.62 & 32.52 & 86.63 \\
\hline & 2300 & 32.77 & 88.33 & 32.77 & 88.30 & 32.78 & 88.28 & 32.80 & 88.16 & 32.80 & 88.15 & 32.80 & 88.16 \\
\hline & 2350 & 33.08 & 89.85 & 33.07 & 89.82 & 33.10 & 89.80 & 33.12 & 89.68 & 33.11 & 89.67 & 33.10 & 89.69 \\
\hline & 2400 & 33.41 & 91.35 & 33.39 & 91.33 & 33.42 & 91.32 & 33.46 & 91.19 & 33.44 & 91.18 & 33.43 & 91.20 \\
\hline & 2450 & 33.76 & 92.85 & 33.75 & 92.82 & 33.77 & 92.81 & 33.82 & 92.68 & 33.80 & 92.68 & 33.79 & 92.70 \\
\hline & 2500 & 34.15 & 94.33 & 34.15 & 94.31 & 34.13 & 94.30 & 34.21 & 94.17 & 34.20 & 94.17 & 34.18 & 94.19 \\
\hline & 2550 & 34.58 & 95.80 & 34.60 & 95.79 & 34.52 & 95.76 & 34.63 & 95.65 & 34.63 & 95.65 & 34.60 & 95.66 \\
\hline & 2600 & 35.05 & 97.26 & 35.11 & 97.25 & 34.92 & 97.23 & 35.09 & 97.12 & 35.10 & 97.12 & 35.08 & 97.13 \\
\hline \multirow{14}{*}{ High } & 2350 & 3 & 89.82 & 33.12 & 89.82 & 33.19 & 89. & 1 & 89.66 & 33.19 & 89.69 & 33.23 & 89.65 \\
\hline & 2400 & 33.45 & 91.33 & 33.47 & 91.34 & 33.51 & 91.32 & 33.53 & 91.19 & 33.50 & 91.20 & 33.55 & 91.18 \\
\hline & 2450 & 33.80 & 92.83 & 33.83 & 92.85 & 33.84 & 92.82 & 33.87 & 92.70 & 33.83 & 92.70 & 33.89 & 92.69 \\
\hline & 2500 & 34.16 & 94.32 & 34.20 & 94.34 & 34.18 & 94.30 & 34.23 & 94.19 & 34.18 & 94.19 & 34.24 & 94.18 \\
\hline & 2550 & 34.54 & 95.79 & 34.58 & 95.81 & 34.55 & 95.77 & 34.60 & 95.67 & 34.56 & 95.66 & 34.60 & 95.66 \\
\hline & 2600 & 34.95 & 97.25 & 34.98 & 97.27 & 34.93 & 97.23 & 34.99 & 97.14 & 34.96 & 97.13 & 34.99 & 97.12 \\
\hline & 2650 & 35.38 & 98.70 & 35.40 & 98.71 & 35.34 & 98.67 & 35.40 & 98.58 & 35.39 & 98.57 & 35.40 & 98.56 \\
\hline & 2700 & 35.85 & 100.13 & 35.85 & 100.13 & 35.78 & 100.10 & 35.85 & 100.01 & 35.85 & 100.01 & 35.85 & 99.99 \\
\hline & 2750 & 36.35 & 101.55 & 36.34 & 101.54 & 36.26 & 101.52 & 36.33 & 101.42 & 36.35 & 101.43 & 36.33 & 101.41 \\
\hline & 2800 & 36.89 & 102.95 & 36.87 & 102.94 & 36.77 & 102.92 & 36.86 & 102.82 & 36.89 & 102.83 & 36.86 & 102.81 \\
\hline & 2850 & 37.49 & 104.33 & 37.46 & 104.32 & 37.34 & 104.30 & 37.44 & 104.20 & 37.47 & 104.21 & 37.44 & 104.19 \\
\hline & 2900 & 38.15 & 105.70 & 38.11 & 105.69 & 37.97 & 105.67 & 38.08 & 105.57 & 38.10 & 105.58 & 38.09 & 105.56 \\
\hline & 2950 & 38.88 & 107.05 & 38.86 & 107.04 & 38.68 & 107.02 & 38.81 & 106.92 & 38.79 & 106.94 & 38.83 & 106.91 \\
\hline & 3000 & 39.72 & 108.39 & 39.72 & 108.38 & 39.48 & 108.35 & 39.65 & 108.25 & 39.55 & 108.28 & 39.69 & 108.25 \\
\hline
\end{tabular}

a Temperature in $\mathrm{K}$.

Heat capacity in $\mathrm{J} \mathrm{mol}^{-1} \mathrm{~K}^{-1}$.

Electrical resistivity in $10^{-8} \Omega \mathrm{m}$. 
TABLE A-2. Experimental results on heat capacity and electrical resistivity of tantalum-2

\begin{tabular}{|c|c|c|c|}
\hline Range & $\begin{array}{l}T \\
\mathrm{~K}\end{array}$ & $\begin{array}{c}c_{p} \\
\mathrm{~J} \mathrm{~mol}^{-1} \mathrm{~K}^{-1}\end{array}$ & $\underset{10^{-8} \Omega \mathrm{m}}{\rho}$ \\
\hline \multirow{7}{*}{ Low } & 1900 & 31.02 & 76.29 \\
\hline & 1950 & 31.20 & 77.90 \\
\hline & 2000 & 31.40 & 79.50 \\
\hline & 2050 & 31.64 & 81.09 \\
\hline & 2100 & 31.90 & 82.66 \\
\hline & 2150 & 32.20 & 84.22 \\
\hline & 2200 & 32.52 & 85.78 \\
\hline \multirow{10}{*}{ Med. } & 2100 & 31.88 & 82.72 \\
\hline & 2150 & 32.11 & 84.29 \\
\hline & 2200 & 32.36 & 85.85 \\
\hline & 2250 & 32.62 & 87.40 \\
\hline & 2300 & 32.90 & 88.94 \\
\hline & 2350 & 33.21 & 90.47 \\
\hline & 2400 & 33.54 & 91.98 \\
\hline & 2450 & 33.90 & 93.48 \\
\hline & 2500 & 34.30 & 94.98 \\
\hline & 2550 & 34.74 & 96.46 \\
\hline \multirow{14}{*}{ High } & 2350 & 33.21 & 90.43 \\
\hline & 2400 & 33.54 & 91.96 \\
\hline & 2450 & 33.88 & 93.47 \\
\hline & 2500 & 34.23 & 94.97 \\
\hline & 2550 & 34.61 & 96.45 \\
\hline & 2600 & 35.00 & 97.92 \\
\hline & 2650 & 35.42 & 99.37 \\
\hline & 2700 & 35.88 & 100.81 \\
\hline & 2750 & 36.37 & 102.23 \\
\hline & 2800 & 36.90 & 103.63 \\
\hline & 2850 & 37.49 & 105.02 \\
\hline & 2900 & 38.15 & 106.39 \\
\hline & 2950 & 38.89 & 107.75 \\
\hline & 3000 & 39.73 & 109.08 \\
\hline
\end{tabular}

TABLE A-3. Experimental results on heat capacity and electrical resistivity of tantalum-3 and tantalum-4

\begin{tabular}{c|c|c|c|c}
\hline \hline \multirow{2}{*}{ Temperature } & \multicolumn{2}{|c|}{ Tantalum-3 } & \multicolumn{2}{c}{ Tantalum-4 } \\
\cline { 2 - 5 } $\mathrm{K}$ & $\begin{array}{c}c_{p} \\
\mathrm{~J} \mathrm{~mol}-1 \mathrm{~K}^{-1}\end{array}$ & $\begin{array}{c}\rho \\
10^{-8} \Omega \mathrm{m}\end{array}$ & $\begin{array}{c}c_{p} \\
\mathrm{~J} \mathrm{~mol}-1 \mathrm{~K}^{-1}\end{array}$ & $\begin{array}{c}\rho \\
10^{-8} \Omega \mathrm{m}\end{array}$ \\
\hline & & & & \\
2950 & 38.88 & 106.82 & 38.67 & 106.64 \\
3000 & 39.42 & 108.14 & 39.48 & 107.96 \\
3050 & 40.15 & 109.45 & 40.42 & 109.28 \\
3100 & 41.12 & 110.75 & 41.50 & 110.58 \\
3150 & 42.43 & 112.04 & 42.77 & 111.87 \\
3200 & 44.22 & 113.32 & 44.31 & 113.15 \\
\hline
\end{tabular}

TABLE A-4. Experimental results on normal spectral emittance of tantalum at $\lambda=650 \mathrm{~nm}$

\begin{tabular}{c|r}
\hline$T$ & $\epsilon_{N, \lambda}$ \\
$\mathrm{K}$ & 0.414 \\
1999 & .411 \\
2038 & .409 \\
2076 & .408 \\
2115 & .406 \\
2154 & .406 \\
2192 & .405 \\
2231 & .405 \\
2269 & .406 \\
2307 & .405 \\
2458 & .404 \\
2528 & .402 \\
2597 & .401 \\
2664 & .400 \\
2730 & .399 \\
2794 & .399 \\
2857 & .398 \\
2917 & .398 \\
2975 & \\
\hline
\end{tabular}

TABLE A-5. Experimental results on hemispherical total emittance of tantalum

\begin{tabular}{c|c}
\hline$T$ & $\epsilon$ \\
K & \\
\hline First Series & \\
2324 & 0.315 \\
2324 & .314 \\
2328 & .319 \\
2328 & .319 \\
2640 & .326 \\
2640 & .330 \\
2650 & .329 \\
2650 & .328 \\
2961 & .342 \\
2961 & .341 \\
2975 & .345 \\
2975 & .344 \\
& \\
Second Series & \\
2319 & 0.307 \\
2319 & .305 \\
2325 & .311 \\
2325 & .309 \\
2646 & .321 \\
2646 & .321 \\
2655 & .325 \\
2655 & .324 \\
2980 & .338 \\
2980 & .338 \\
2994 & .340 \\
2994 & .340 \\
\hline
\end{tabular}




\section{References}

[1] Cezairliyan, A., Morse, M. S., Berman, H. A., and Beckett, C. W., High-speed (subsecond) measurement of heat capacity, electrical resistivity, and thermal radiation properties of molybdenum in the range 1900 to 2800 K. J. Res. Nat. Bur. Stand. (U.S.), 74A (Phys. and Chem.), No. 1, 65-92 (Jan.Feb. 1970).

[2] Cezairliyan, A., High-speed methods of measuring specific heat of electrical conductors at high temperatures, High Temp.-High Pres., 1, 517 (1969).

[3] Cezairliyan, A., McClure, J. L., Morse, M. S., and Beckett, C. W., Measurement of Heat Capacity of Tantalum in the Range 1900 to $3000 \mathrm{~K}$ by a Pulse Heating Method. Fifth Symposium on Thermophysical Properties (Boston), ASME, New York (1970).

[4] Lowenthal, G. C., The specific heat of metals between $1200 \mathrm{~K}$ and $2400 \mathrm{~K}$, Australian J. Phys. 16, 47 (1963).

[5] Rasor, N. S., and McClelland, J. D., Thermal properties of graphite, molybdenum, and tantalum to their destruction temperatures, J. Phys. Chem. Solids 15, 17 (1960).

[6] Taylor, R. E., and Finch, R. A., The specific heats and resistivities of molybdenum, tantalum, and rhenium, J. LessCommon Metals 6, 283 (1964).

[7] Jaeger, F. M., and Veenstra, W. A., The exact measurement of the specific heats of solid substances at high temperatures (vanadium, niobium, tantalum, and molybdenum), Rec. Trav. Chim. 53, 677 (1934).

[8] Hoch, M., and Johnston, H. L., A high-temperature drop calorimeter, The heat capacities of tantalum and tungsten between 1000 and $3000 \mathrm{~K}$, J. Chem. Phys. 65, 855 (1961).

[9] Schultz, H., "Quenching of Vacancies in Tungsten," in Lattice Defects in Quenched Metals, R. M. J. Cotterill, M. Doyama, J. J. Jackson and M. Meshi, Eds. (Academic Press, New York, 1965), p. 761.

[10] Meakin, J. D., Lawley, A., and Koo, R. C., "Vacancy Loops in Quenched Molybdenum," in Lattice Defects in Quenched Metals, R. M. J. Cotterill, M. Doyama, J. J. Jackson, and M. Meshi, Eds. (Academic Press, New York, 1965), p.767.

[11] Hultgren, R., Orr, R. L., Anderson, P. D., and Kelley, K. K. Selected Values of Thermodynamic Properties of Metals and Alloys (John Wiley, New York, 1963).

[12] Foley, G. M., High-speed optical pyrometer, Rev. Sci. Instr. 41, 827 (1970).

[13] DeVos, J. C., Evaluation of the quality of a blackbody, Physica 20, 669 (1954).

[14] International Practical Temperature Scale of 1968, Metrologia 5, 35 (1969).
[15] Compt. Rend. of the 21st Conference of the International Union of Pure and Applied Chemistry, Montreal (1961), Report of the Committee on Atomic Weights, p. 284

[16] Tietz, T. E., and Wilson, J. W., Behavior and Properties of Refractory Metals (Stanford University Press, California, 1965), p. 28.

[17] Cezairliyan, A., High-speed methods of measuring thermophysical properties at high temperatures, Rev. Int. Hautes Tempér. et Réfract. 7, 215 (1970).

[18] Worthing, A. G., Physical properties of well seasoned molybdenum and tantalum as a function of temperature, Phys. Rev. 28, 190 (1926).

[19] Malter, L., and Langmuir, D. B., Resistance, emissivities and melting point of tantalum, Phys. Rev. 55, 743 (1939).

[20] Hörz, G., Emissionsvermögen und elektrischer Widerstand von Tantal bei hohen Temperaturen. Z. Metallk. 57, 871 (1966).

[21] Peletskii, V. E., and Voskresenskii, V. Ya., Thermophysical properties of tantalum at temperatures above $1000{ }^{\circ} \mathrm{C}$. High Temperature 4, 329 (1966).

[22] Neimark, B. E., and Voronin, L. K., Thermal conductivity, specific electrical resistivity, and total emissivity of refractory metals at high temperatures, High Temperature 6, 999 (1968).

[23] Petrov, V. A., Chekhovskoi, V. Ya., and Sheindlin, A. E., Integral hemispherical radiating power and specific electrical resistance of tantalum in the temperature interval 1200 2800 K. High Temperature 6, 525 (1968).

[24] Allen, R. D., Glasier, L. F., and Jordan, P. L., Spectral emissivity, total emissivity, and thermal conductivity of molybdenum, tantalum, and tungsten above $2300 \mathrm{~K}$, J. Appl. Phys. 31, 1382 (1960).

[25] White, G. K., and Woods, S. B., Electrical and thermal resistivity of the transition elements at low temperatures, Phil. Trans. Royal Soc. (London) 25 1, 273 (1959).

[26] Tye, R. P., Preliminary measurements on the thermal and electrical conductivities of molybdenum, niobium, tantalum, and tungsten, J. Less-Common Metals 3, 13 (1961).

[27] Powell, R. W., Thermal conductivity: A review of some important developments, Contemp. Phys. 10, 579 (1969).

[28] Gshneidner, K. A., "Physical Properties and Interrelationships of Metallic and Semimetallic Elements," in Solid State Physics, Vol. 16, F. Seitz and D. Turnbull, Eds. (Academic Press, New York, 1965), p. 275.

(Paper 75Al-644) 